\section{La eugenesia tardía en Argentina y su estereotipo de familia, segunda mitad del siglo XX}

\section{Late eugenics in Argentina and its family stereotype, second half of the twentieth century}

Marisa A. Miranda

Investigadora, Consejo Nacional de Investigaciones Científicas y Técnicas; profesora, Universidad Nacional de la Plata. La Plata - Buenos Aires - Argentina

mmiranda2804@gmail.com
MIRANDA, Marisa A. La eugenesia tardía en Argentina y su estereotipo de familia, segunda mitad del siglo XX. História, Ciências, Saúde - Manguinhos, Rio de Janeiro, v.25, supl., ago. 2018, p.33-50.

\section{Resumen}

Este artículo se ocupa de delinear las características principales del estereotipo de familia promovido por la institución emblemática del eugenismo argentino, la Sociedad Argentina de Eugenesia, organización que, nacida en 1945, pervivió en el país hasta la década de 1970. Se exploran aquí las conductas esperables tanto del hombre/marido como de la mujer/esposa; develándose los principales comportamientos requeridos para constituir esa familia ideal, organizada en torno a patrones sustentados en una pretendida moral sexual de sesgo eminentemente confesional.

Palabras clave: eugenesia tardía; tardoeugenismo; familia; Argentina; siglo XX.

Abstract

This article seeks to outline the main features of the stereotype of family promoted by the emblematic institution of the Argentine eugenics movement, the Argentine Eugenics Society (Sociedad Argentina de Eugenesia), an organization founded in 1945 that remained active in the country until the 1970s. It explores the conduct expected both of the man/husband and of the woman/wife, and shows the principal behaviors required to constitute the ideal family, the outlines of which were based on set of sexual moral with an eminently religious bias.

Keywords: late eugenics; family; Argentina; twentieth century. 
$\mathrm{L}$ as lecturas y adaptaciones de la eugenesia, disciplina definida en 1883 por Francis Galton en Inquires into human faculty and its developement como ciencia del cultivo de la raza, aplicable al hombre, a las bestias y a las plantas (Álvarez Peláez, 1988, p.79-130), no conformaron un discurso monolítico. En efecto, ya desde su enunciación decimonónica y, más aún, durante el siglo XX, existieron diversas formulaciones vinculadas, en general, a las particularidades socioculturales de cada Estado. Así, se suele diferenciar historiográficamente a la eugenesia latina de la anglosajona; explicándose la pervivencia de la primera en el período de la Guerra Fría por su cercanía a la Iglesia católica y su oposición a las intervenciones directas sobre los órganos reproductivos con la consiguiente prevalencia del factor ambiental en lugar del duro concepto de "raza" identificable con la política del Tercer Reich y deudora de la vertiente anglosajona (Stepan, 1991; Turda, Gillette, 2014, p.240). Sin embargo, más allá de estas disimilitudes, puede convenirse que ambas versiones fueron sustentadas con cierta legitimidad otorgada a la gestión pública de la vida privada. ${ }^{1}$

La eugenesia latina, cuyos orígenes podrían localizarse en Italia en las primeras décadas del siglo XX, encontró en el médico y luego en el sacerdote Agostino (Edoardo) Gemellia un protagonista central que integraría los postulados del creciente movimiento eugénico internacional y de la Iglesia católica. ${ }^{2}$ Gemelli tuvo una participación central en el diseño de las políticas demográficas de impronta eugenésica implementadas por el fascismo italiano; definiendo en su intervención en el primer Congreso Italiano di Eugenética Sociale, celebrado en 1924, en Milán, una problemática sobre la que se terminaría conformando el núcleo constitutivo de una corriente de pensamiento. Allí disertó sobre "Eugenetica e religione", sosteniendo que el catolicismo era "también" una doctrina eugénica, para reclamar que, en un país católico como Italia, los eugenistas médicos debían trabajar en colaboración con la Iglesia. La cooperación entre religión y eugenesia revelaba la armonía fundamental que debía existir entre la fe y la ciencia (Gemelli, 1924, p.732-733), para que en lugar de la "incultura" de los que proponían la esterilización obligatoria de los criminales, prosperara la "eugenética social" católica (p.735). En su misión por realizar la "más racional de las acciones eugénicas", la Iglesia impulsaba la castidad de "quienes traerían al mundo seres fatalmente afectados de una enfermedad hereditaria" (p.747-748), concluyendo que la Iglesia, lejos de ser enemiga de la eugenesia, operaba como su complemento imprescindible, ya que "la norma eugénica tendrá una aplicación más eficaz en su integración con la moral católica" (Gemelli, 1924, p.750; Vallejo, Miranda, 2014b). Sobre estas bases epistemológicas se sustentarían los discursos que, durante el siglo XX, procuraron armonizar eugenesia y religión. ${ }^{3}$

Esta vertiente latina de la ciencia de Galton adquirió fuerte impulso en países de oriente católico, constituyendose la Argentina (a través de sus conservadoras élites dirigentes) en un faro regional en la materia, tal como lo demuestran las diversas redes interestatales e interinstitucionales generadas a instancia suya (Miranda, Vallejo, 2012). Y, asumiendo diversos estadios en el interior de la composición del campo, denominamos tardo eugenesia o eugenesia tardía a las enunciaciones de la disciplina posteriores a 1945 y que se mantuvieron hasta las postrimerías del siglo XX (Miranda, 2007). Cabe destacar, no obstante, que el adjetivo "tardía" resulta excedentario del ámbito argentino para abarcar diversos países de la región, como Perú y Bolivia, por ejemplo; y obedece a su subsistencia 
y/o formulación luego del Holocausto. Así, esta etapa tuvo sus inicios en dos acontecimientos que, si bien de dimensiones muy diversas, se constituirían en clave para la temática. En el marco internacional, la finalización de la Segunda Guerra Mundial y la exhumación de los horrores nazi, avalados por una pretensión pseudo científica de mejora racial; y, en el marco nacional, la trascendente escisión institucional que se diera, también en 1945, con la fundación de la Sociedad Argentina de Eugenesia como contrapunto de la Asociación Argentina de Biotipología, Eugenesia y Medicina Social, creada en 1932, y que luego fuera absorbida en la órbita estatal. En este sentido, cabe enfatizar que el protagonismo adquirido por la primera durante el lapso en estudio le permitió fundar, en 1957, la única facultad de eugenesia del mundo (Vallejo, Miranda, 2017).

En las siguientes páginas se esbozan las características principales del tardo eugenismo de neto corte latino, focalizando particularmente en el estereotipo de familia promovido por la institución emblemática del período, la mencionada Sociedad Argentina de Eugenesia, organización nacida a instancias del abogado Carlos Bernaldo de Quirós que pervivió en el país hasta entrada la década de $1970 .{ }^{4}$ En este sentido, se visibilizan las expectativas conductuales respecto al hombre/marido como a la mujer/esposa; develándose los principales comportamientos requeridos, en nombre de esa disciplina victoriana, para constituir una familia ideal, basada - cabe anticipar - en patrones articulados en una pretendida moral sexual. Esas lecturas tardías de la "ciencia" de Galton constituyeron una ideología funcional para el mantenimiento de un status quo sexual, reproductivo y familiar por entonces en crisis terminal; el cual resulta, a la vez, demostrativo de las profundas imbricaciones entre biología y política, inmanentes a la eugenesia.

Ahora bien, en vez de comenzar nuestras reflexiones con las diversas posturas sociológicas y antropológicas respecto al concepto de familia, ${ }^{5}$ nos valdremos del conformado en su misma fuente de enunciación - es decir, el discurso autorizado por el tardoeugenismo - y, desde ahí, concentraremos la atención en aspectos considerados medulares para la consolidación del estereotipo familiar. En este sentido, según la tardoeugenesia latina, la familia era el vínculo jurídico, pero también moral, de carácter monógamo e indisoluble entre hombre y mujer calificados durante el noviazgo como "aptos" para concebir descendencia eugénica. Una unión que, además, estaba presidida por un marcado reforzamiento de la tradicional asignación de roles de género, en cuyo contexto, Estado y religión oficiaban como elementos coactivos en pos de impedir su "disgregación". La familia eugénica quedaba, entonces, distanciada del concepto sociológico que la caracteriza como grupo humano en el cual se desarrollan lazos de solidaridad y procreación, para identificarse más con un concepto normativo, de donde su legitimidad constitutiva encontraba sustanciales avales de orden humano y de orden divino.

Procurando destacar aquellos aspectos centrales de la familia modélica según la tardo eugenesia latina, nos concentraremos en analizar sus discursos en cuestiones tales como la unión heterosexual; la indisolubilidad de un vínculo matrimonial con potencialidad de generar individuos eugénicamente aptos; el afianzamiento de roles de género y, desde ese contexto, la promoción del fomento de la natalidad y su paralela proscripción de la anticoncepción. 


\section{La heteronormatividad eugénica ante la homosexualidad}

En el núcleo mismo de la tesis de Galton se ubica, por principio, el control del cuerpo, el cual, en la eugenesia latina, sería complementado por la exigencia de un vínculo matrimonial previo y legítimo en miras a la consolidación de una familia. Y, a partir de esa inmanencia del hecho reproductivo en toda propuesta eugenésica, la represión de la homosexualidad constituía una incongruencia a resolver. En este sentido, cobró entidad una particular argumentación de cierta impronta neolamarckiana: el homosexual, por su sola cercanía física, exaltaba pasiones homoeróticas en hombres heterosexuales, de donde se legitimaba su interdicción.

Sobre esta cuestión no constituye un dato menor que, muy próximo al inicio del período tardo eugénico, se diera en Argentina un acontecimiento que reflejaría las dos caras de la moneda: la heteronormatividad eugénica, por un lado, y la tradición homofóbica de las elites gobernantes, por otro. El denominado "Escándalo de los cadetes" fue un hecho protagonizado por un grupo de cadetes del Colegio Militar de la Nación quienes, en 1942, serían fotografiados desnudos y en poses sugerentes junto a otros hombres, denotando sus inclinaciones homosexuales. Este episodio fue vinculado a la ineficacia del sistema abolicionista en materia de reglamentación de la prostitución instaurado en 1936. La explicación dada era clara: ante la inexistencia de prostíbulos legalizados, los hombres buscaban placer mediante el contacto sexual con sus congéneres. Y, en respuesta a ello, el gobierno de facto de Edelmiro J. Farell dictó, en 1944, un decreto que autorizaba la instalación de "casas de tolerancia", otrora prohibidas por la norma legal antivenérea que ahora modificaba. Los fundamentos esgrimidos para esa reformulación se basaron en otorgar entretenimiento femenino a los soldados apostados en bases remotas y evitar, según se creía, el riesgo de que ante la abstención sexual con mujeres los militares pretendieran saciar su apetito con hombres. Mediante esta estrategia se procuraba impedir que los miembros del "cuerpo viril de la Nación" cayeran en perversiones sexuales; y estimular, a su vez, la heterosexualidad tradicional y las instituciones del matrimonio y de la familia.

Este emblemático hecho influyó en los cuatro anteproyectos de ley presentados en 1949 por la Sociedad Argentina de Eugenesia, con la finalidad de incluir la mirada eugenésica en la normativa en vigor, o mejor aún, de eugenizar legislativamente al país. ${ }^{6}$ Si bien ninguna de estas propuestas llegó a tener trámite parlamentario, las mismas poseen un fundamental valor en cuanto discurso tardo eugénico. En este sentido, quedaba bien delineada la posición de la Sociedad Argentina de Eugenesia respecto al valor de la educación por sobre la norma; llegando a afirmarse, una década después, que la ley jamás podría sustituir a las enseñanzas positivas de la eugenesia, ni preservar el cimiento del niño, la selección responsable de los genitores o el "cultivo humano" de padres, esposos e hijos, entre otras cosas (Bernaldo de Quirós, 1957b).

Sin embargo, más allá de que ciertas tensiones localizadas en el interior del campo eugénico argentino impidieran la concreción integral de la iniciativa, aquel plan destinado a cerrar el "círculo completo" dentro del cual se desarrollaba la "lucha a favor de la raza y del biotipo argentino" (Colombo, 1949, p.915) dejó su impronta en un particular clima de 
ideas, cuyos frutos vieron a la luz a partir del derrocamiento de Juan Domingo Perón en 1955, momento en el cual el tardo eugenismo llegaría en el país a su máximo esplendor.

Ahora bien, pese a que la Sociedad Argentina de Eugenesia planteó su combate a la homosexualidad desde la educación sexual - variable ambiental por excelencia -, el fantasma de su anclaje genético también conservaba vigencia, tal como lo reflejan las palabras del vicepresidente de esa institución, Benjamín Spota, en ocasión de una conferencia brindada en el Ateneo Ibero-Americano (Spota, 1947). A partir de un relato que adscribe al del psiquiatra franquista Antonio Vallejo Nágera, ${ }^{7}$ Spota $(1947$, p.308) afirmaba que los homosexuales eran "verdaderos enfermos psíquicos" que, atento a su "personalidad psicopática", merecían tratamiento, protección y en todo caso reclusión, pues "el episodio y síndrome sexual es [era] por lo habitual, expresión de la desintegración del sentido moral y del núcleo de la personalidad". De esta manera, existía en la homosexualidad un fundamental sinergismo entre lo hereditario y lo ambiental, en cuyo contexto ambos factores, herencia y ambiente, actuaban de manera complementaria (Spota, 1947, p.300). Se debía procurar, entonces, combatir al homosexualismo activo y pasivo, al onanismo, en cuanto desviaciones patológicas de la sexualidad; de donde era menester que la reproducción fuera antecedida por una educación que incorporase como valor supremo la responsabilidad procreacional, ${ }^{8}$ para que no fueran el azar o la desgracia los que decidieran el engendramiento, sino que éste resultara del amor consciente, de la conducta inteligentemente controlada por ambos genitores, a fin de que no naciera "un fruto subestimado y desdichado, hijo de la manifestación vegetativa del hambre sexual, con taras biológicas, sociales, económicas y morales" (Argentina, 1950, p.83). Quedaba claro, pues, que desde esta perspectiva el sexo estaba "al servicio de la perpetuidad de la especie" (Domenech, 1958, p.232).

La enseñanza eugenésica debía concentrarse, entre otras cosas, en contrarrestar la predisposición de quienes, teniendo padres o abuelos "sexualmente congestionados" o "crónicamente excitados", encontraban en ese medio los estímulos directos que activaban aquella perversión ancestral. De aquí la centralidad de padres actuando como educadores, del ambiente, de los ejemplos, las costumbres, la fuerza de las tradiciones, la calidad de las relaciones sociales, los hábitos fisiológicos, los alimentos, los tóxicos, la prostitución y las modas, las confiterías galantes, el cine, la televisión, la radio, el teatro y las revistas, que vivaban la publicidad malsana (Bernaldo de Quirós, 1960a, p.89).

Además, la propuesta de la Sociedad Argentina de Eugenesia se afirmaba en la castidad y la continencia sexual, exaltando el matrimonio eugénico, la procreación, la familia y el orden, afianzando con ella su posición en contra de lo que denominaba "sexopatía" homosexual (El homosexualismo..., 1967, p.251). Una proclama que se reforzaría a través de las críticas publicadas en las páginas de su principal órgano de difusión, la revista Estudios Eugenésicos respecto a la posición de un clérigo norteamericano que propiciaba un tratamiento inclusivo hacia los homosexuales (Otra vez..., 1968).

Y, desde el homófobo (o, mejor aún, heterófobo) eugenismo argentino se continuó trabajando en pos de la construcción de un arquetipo mítico que respetara un orden, como el que mesiánicamente pretendió instaurar Juan Carlos Onganía, al frente de la Revolución Argentina que en 1966 tomó el gobierno. De esta manera, la afinidad ideológica entre la Sociedad Argentina de Eugenesia y la dictadura de Onganía era más 
que evidente, elogiándose la política de subsidios familiares impulsada desde el régimen golpista, que, se aseguraba, ponía en práctica el enfoque eugenésico (La política..., 1969). En concordancia, el gobierno de facto había planteado como objetivo la consolidación de los "valores espirituales y morales del pueblo argentino" para lograr así un afianzamiento de una "tradición espiritual inspirada en los ideales de libertad y dignidad de la persona humana", patrimonio de la civilización "occidental y cristiana", que bregaba por mantener con firmeza el "estilo de vida y los grandes fines morales" que hacían la "esencia de la nacionalidad" (Objetivos..., 1967).

\section{Monogamia e indisolubilidad del matrimonio entre seres eugénicamente aptos}

Teniendo en cuenta los cambios sociales operados con la segunda posguerra, la pretensión modélica de un vínculo monógamo e indisoluble fue requiriendo, con el devenir del siglo $\mathrm{XX}$, de una mayor presencia de los saberes normativos tanto en la selección de quiénes debían casarse, como también de quiénes debían hacerlo entre sí. De esta manera, el consejo prenupcial durante el noviazgo, a cargo de un médico o de un confesor, permitía articular la discursividad jurídico-política organizada en torno al régimen legal del matrimonio con la variante eugenésica latina, sustentada en las disposiciones de la encíclica Casti connubii, dictada por el papa Pío XI en diciembre de 1930. El consejo operaba, ya desde entonces, como un dispositivo de control social a partir del cual se desalentaba la procreación de los "degenerados" al desaconsejarse su matrimonio y, destacándose, desde la Asociación Argentina de Biotipología, Eugenesia y Medicina Social, la primacía de la "conciencia del individuo de su propio valor como reproductor de la especie" (Rossi, 1944, p.155) se reforzaba la legitimidad de su propuesta de "selección eugenésica" de los futuros contrayentes (p.132). Recién a partir de esas uniones "selectas", y solo sobre ellas, se instrumentarían variadas medidas poblacionistas en el marco de un proyecto tendiente a "elevar al máximo la fecundidad de los cepos sanos con intensa propaganda demográfica" (p.121).

Benjamín Spota (1947, p.306), por ejemplo, proponía la confección de una ficha eugénica oficial que detallara diversos aspectos físicos, psicológicos y sociales de los habitantes, con la finalidad de hacer comprender a ciertas parejas lo "inconveniente del acoplamiento" ante la incidencia disgenésica, o el peligro de exteriorización de caracteres recesivos. ${ }^{9}$ Mientras que Bernaldo de Quirós (1957b, p.128) objetaría a la Declaración de los Derechos Humanos de 1948, considerándola un documento teórico, sin alma ni principios eugénicos, atento a que no contemplaba como "derechos fundamentales" el de "selección consciente, instruida y responsable eugenésicamente" para el matrimonio ni el de "nascencia eugénica del hijo", directa consecuencia de un "cruzamiento eugenésico".

Las uniones "indeseables", imputables a un "sistema fallido de formación humana familiar" (Bernaldo de Quirós, 1957b, p.73), deberían ser combatidas mediante la creación de escuelas de formación humana, las que dictarían cursos sobre organización humana eugénica. La eugenesia quirosiana partía, pues, del principio de que toda existencia humana estaba supeditada a que ambos sexos fueran sanos, libres, instruidos, conscientes y responsables para la función genésica; siendo fundamental aceptar y estimular una selección consciente y responsable, por el biotipo sano, de un cónyuge futuro con iguales cualidades, 
reclamando una educación capacitadora de las juventudes, la dedicación activa de las escuelas (oficiales y privadas) y la colaboración inteligente de las instituciones fundadas en tal sentido. Solo de esa forma se lograría neutralizar "el amor irresponsable e incivil, los acoplamientos llamados 'naturales', los hijos del azar y de la disgenesia, el libertinaje en todas sus formas, y el interés egoísta contracepcional y monotecnofílico o del hijo único" (Bernaldo de Quirós, s.f., p.333-334).

Aún entrados los años 1970, Quirós insistiría respecto a la necesidad de preparar para el matrimonio a los futuros esposos, padres y madres, para lo cual formulaba un particular cuerpo de preceptos que denominó "Decálogo pre-matrimonial" y "Decálogo pre-concepcional". Entre la curiosa serie de consignas establecidas allí, se destaca el afianzamiento de la necesidad de aptitud nupcial eugénica tanto del varón como de la mujer a la que se le adunan factores económicos y familiares, sugiriendo el autor la trascendencia en el éxito de la unión de un conocimiento acabado de los futuros contrayentes. Se refuerza, así, el requisito de que ninguno de los dos tuviera "fallas morales", "desprestigio social" o "mala conducta" (Bernaldo de Quirós, 1972, p.135-137).

A su vez, entre los factores considerados por Quirós como favorables al matrimonio se encontraban la aptitud física, fisiológica, psíquica y moral; la simpatía, conocimiento y comprensión recíprocas; la capacidad para la cordialidad y la tolerancia mutua; la vocación para la vida conyugal, los hijos y la familia; la asistencia, convivencia, fidelidad y desempeño de tareas según rígidos roles de género; la madurez, seriedad y equilibrio (lograda, según Quirós, al alcanzar la novia 22 ó 23 años de edad y el novio 25 ó 27); la coincidencia en el sentido y propósitos de la vida; que ambos tuviesen cultura y religiosidad "homogéneas"; así como que su condición social y económica fuera "nivelada" o "compensada". Evaluaba, en cambio, como desfavorables, la primacía de los "instintos" por sobre la formación humanogógica; que el matrimonio fuera considerado como un fin (y no como un medio) de perpetuación y perfeccionamiento; que descansara en un "mito" como el del candor, la "personalidad", la familia tal o cual, o la influencia; que existiera cansancio moral, represión o tensión, en uno o en los dos; que uno tuviera una marcada tendencia al criticismo en menoscabo del otro, o un autoritarismo cruel e indebido; que existiera injuria de palabra o agresividad de hecho; que se careciera de capacidad para la tolerancia y el amor; que la ociosidad, la abulia de uno perjudicara al otro en lo moral y en lo material; que el excesivo espíritu de trabajo de uno comprometiera o anulara la vida normal y el cumplimiento de otros deberes; o que los vicios de uno hicieran imposible la vida en común (Bernaldo de Quirós, 1972, p.124-125).

De esta forma, el consejo prenupcial, articulado de manera complementaria al certificado médico obligatorio, instaurado en el país desde la década de 1930 para los hombres y ampliado, en la década de 1960 para las mujeres, procuraba detectar la capacidad de los esposos para la vida en común y la reproducción eugénica. Todo ello en el marco de un matrimonio irremediablemente indisoluble, cuya estabilidad afectiva se creía sustentada en un cuerpo y una psiquis que le permitieran al sujeto cumplir, en forma satisfactoria, con su principal función social, la función reproductiva. ${ }^{10}$

Sin embargo, una significativa cuestión quedaba sin resolver. En efecto, el marco científico desde donde se reforzó la conveniencia biológica de conservar una estructura 
de familia tradicional contenía en su seno una sustancial incongruencia, radicada en la contradicción latente entre los planteos eugenésicos latinos (desde cuyo ascendiente católico se imponía, como anticipamos, la indisolubilidad del vínculo matrimonial) y la eventualidad de la adquisición de una enfermedad disgenésica durante la vigencia de una unión válida. Recordando que la oposición de la Iglesia al divorcio databa desde mucho tiempo antes, cabe poner como ejemplo el texto publicado en 1932 por el político católico Arturo Bas (1932, p.248), donde llamaba a sus lectores a convertirse en abanderados de una "cruzada de argentinidad, combatiendo con todos los recursos a su alcance la implantación de la ley de divorcio en el país", considerando que destruiría las "bases fundamentales de nuestra sociedad: la familia y la propiedad". ${ }^{11}$

Esta desarmonía entre la propuesta eugénica y la doctrina eclesiástica pretendería ser zanjada mediante el instituto jurídico de la "separación con fines eugénicos", cuya característica de dispositivo de control social presentado como una medida sanitaria de orden público, autorizaba el incumplimiento de los derechos-obligaciones de débito conyugal y de cohabitación, facultando al Estado a intervenir en la esfera de la intimidad. Para instrumentarlo, se previó que ante la detección en uno de los cónyuges de una enfermedad potencialmente disgenésica, la cual, de haberse manifestado antes del matrimonio hubiera inhabilitado su celebración, imponía al Estado el deber de intervenir. Esta postura, lejos de entrar en flagrante contradicción con la de la Iglesia, guardaba armonía con los dichos del hispano cardenal Gomá (1943, p.198), quien también propusocomo causa de divorcio temporal a los "peligros graves de alma o cuerpo", incluyendo "una enfermedad contagiosa como lepra".

A partir de esta orientación debe interpretarse la posición asumida por el jurista argentino Enrique Díaz de Guijarro (1944, p.19-28) en la Primera Jornada Peruana de Eugenesia (Lima, 1939). Allí planteó la necesidad de reglamentar el divorcio cuando se revelara o adquiriera una enfermedad crónica, contagiosa o hereditaria, postura que luego reiteraría en la Segunda Jornada Peruana de Eugenesia (Lima, 1943) y en el Segundo Congreso Nacional de Facultades de Derecho (Potosí, 1940).

Asimismo, también uno de los anteproyectos presentados por la Sociedad Argentina de Eugenesia en 1949 establecía como causal de divorcio (obviamente, sin disolución del vínculo matrimonial, ni la consecuente recuperación de la aptitud nupcial) a la "revelación, adquisición o transmisión de las enfermedades venéreas, la lepra y el alcoholismo" (Argentina, 1950, p.41). Ideas éstas recalcadas desde la misma sociedad al propiciar la "separación temporaria de los cónyuges" hasta su curación definitiva o "hasta que el riesgo de contagio" se desvaneciera; llegándose hasta a recomendar el "aborto eugenésico" para el supuesto de que "antes de hacerse efectiva dicha separación" la mujer hubiese quedado encinta y se temiera por la "salud del futuro ser" (Colombo, 1949, p.921). Insistiéndose, luego, en la separación o aislamiento compulsivo de los esposos ya casados, ante la adquisición de una enfermedad que hubiese constituido impedimento matrimonial de orden eugénico (Colombo, 1956b, p.699).

No obstante, las propuestas tardo eugénicas requerían también de una difusión muy amplia. Más allá de la profusa publicidad radial, televisiva y en la vía pública con que contaba la sociedad, también se organizaron en su seno diversos eventos (Vallejo, 2009; 
Vallejo, Miranda, 2005), entre los cuales puede mencionarse el curso dictado por Quirós en 1968 sobre promoción eugénica matrimonial y familiar (Bernaldo de Quirós, 1968b); circunstancia que le permitió explayarse en el tema del matrimonio (eugénico) como presupuesto ineludible para la creación de una familia (también eugénica). En esa ocasión, el fundador de la Sociedad Argentina de Eugenesia no se privaría de recordar las críticas que por entonces ya venía haciendo a un proyecto de creación de Tribunales de Familia. Al respecto, reclamaba que los jueces, miembros de tribunales de familia, asesores y letrados actuantes, debían contar con la formación proporcionada en la mencionada Facultad de Eugenesia, que funcionaba en la órbita del Museo Social Argentino (Bernaldo de Quirós, 1966, p.176).

\section{La mujer (solo) como "madresposa"}

La institución familiar considerada desde el tardo eugenismo argentino requería, de manera impostergable, afianzar el rol otorgado a la mujer, concebida tan solo en cuanto "madresposa", 12 en el contexto de una unión matrimonial (real o potencial) que debía extenderse "hasta que la muerte los separe" (Miranda, 2014). Ahora bien, para explicar la subsistencia de ciertos rasgos, ya por entonces socialmente cuestionados, cabe recordar, una vez más, el protagonismo de diversos actores tradicionales del entramado biopolítico; pero, también, el capital simbólico de un discurso médico-jurídico apoyado en una legalidad que delimitaba, de forma discrecional, en el ámbito de lo legítimo y lo ilegítimo. En esta trama, rígidos roles de género, jerarquizados y por demás diferenciados, involucraron la imposición bajo ropaje científico - de conductas compatibles con una moral sexual a sostener.

Las fisuras paradigmáticas presentadas por esos arcaicos imperativos se incrementaron exponencialmente a partir de la difusión de la anticoncepción hormonal femenina implementada mediante la denominada píldora; ${ }^{13} \mathrm{y}$, con el tiempo, al incremento en el reconocimiento de los derechos sexuales y reproductivos de las mujeres (Gutiérrez, 2009). Desde el campo eugénico local, durante el lapso en análisis, pese a que en paralelo a la consolidación del tardo eugenismo local aquella hermética concepción de roles comenzaba a debilitarse en pos de una imagen de sexualidad femenina "des"-ligada del proceso reproductivo, se revalorizaba el protagonismo de la variable ambiental, a la que se le adjudicaron repercusiones cualitativas tanto a nivel individual como grupal.

Este protagonismo ambiental se expresaba, también en este tema, a partir de una educación sexual obligatoria con fines eugenésicos integrales ${ }^{14}$ que planteaba diversas estrategias concentradas en la formación de seres capaces de "salvaguardar el hogar, prestigiar la familia y preparar al joven para su gobierno genético matrimonial ulterior; luchar contra la inmoralidad y el vicio" (Argentina, 1950, p.81-84).

A su vez, la castidad prenupcial era considerada un valor supremo y la prolificidad promovida después de celebrado un matrimonio bajo los cánones eugenésicos se correspondía con la exaltación de las virtudes de la continencia sexual antes de llegar a esa instancia; de manera tal que la norma pública debía velar por los "hábitos de saneamiento moral y ambiental" del joven, que encontraría en la castidad los grandes beneficios, incluso biológicos, que produce en esa edad "el semen retenido en las vesículas" 
(Bernaldo de Quirós, 1960a, p.97-98). Estas ideas iban en paralelo a la lucha entablada contra la de natalidad, la que también emergía influida por un discurso tendiente a imponer una moral sexual, excedentaria con creces de la "tarea patriótica" de poblar al país. Y, en esa orientación, se advierte una profusa literatura eugénica orientada a luchar contra la anticoncepción femenina, caracterizada como actitud "pregenocida" (Nasio, 1966, p.213). Precisamente, en respuesta a la divulgación de los métodos anticonceptivos y el ejercicio de la libertad reproductiva, desde el tardo eugenismo se insistía en el rol de la "mujer de su casa" o "mujer decente" que sólo era concebida en cuanto madre y cuyo destino preestablecido era el confinamiento en el hogar o el desempeño de tareas tildadas como femeninas, entre las cuales se ubicaban las de educadora de infantes, enfermeras y visitadoras sociales (Miranda, Bargas, 2011), reforzándose, ya desde su niñez, aquel mandato de subalternidad (Seoane, 2006) en el cual su vida quedaba limitada a la función como "productora" de ciudadanos y la obediencia a su contrafigura conyugal masculina, ya en cuanto a goce sexual, ya en cuanto a disponibilidad de su propio cuerpo y toma de decisiones en materia de procreación. En esta sintonía, se afianzaban las distancias físicas y psicológicas que el tardo eugenismo afirmaba encontrar entre mujeres y hombres (Bernaldo de Quirós, 1960b, p.319).

Y, pese a admitirse que la mujer gozaba de los mismos derechos que el hombre, también se advertía que en sus horas libres, calculadas en un tercio del día, estaba "mentalmente intervenida por el juego de la moda, de la calle, del cine y del deporte", "marchitando" con esta actitud su "biología eugenésica y la coconducción moral del pueblo" (Bernaldo de Quirós, 1960b, p.321).

En este marco, se inscriben las ideas de Alfredo Saavedra, fundador en 1931 de la Sociedad Eugénica Mexicana y que mantuviera intensos vínculos con eugenistas argentinos, tales como Carlos Bernaldo de Quirós, Enrique Díaz de Guijarro, Alfredo Fernández Verano y Lázaro Sirlin. Saavedra refería que desde su institución se había realizado una "obra educativa basada en el concepto moral de responsabilidad procreacional"; afirmando el logro de "un clima de sanidad, de limpieza moral al influir constantemente, en mil ocasiones, sobre la conciencia de los padres de familia, especialmente de la mujer mexicana, de los médicos, de los maestros, educadoras, enfermeras y trabajadoras sociales" (Bernaldo de Quirós, 1957a, p.156). Esta postura de la Sociedad Eugénica Mexicana pervivió en su país hasta los años 1960 (Suárez y López Guazo, 1999, 2005, p.114-115; Stern, 2003), prosiguiendo el contacto con la institución argentina. Al respecto, cabe recuperar la misiva, de autoría de Saavedra que fuera publicada a página completa en la revista de la Sociedad Argentina de Eugenesia. En ella, el mexicano se ocupa de un tema crucial en perspectiva eugénica latina: el matrimonio, habilitando a que esa "Carta eugenésica para una hija que se casa" pueda ser entendida, además, como un ejemplo de la viscosidad conceptual de la eugenesia (Miranda, 2013). En efecto, el vocablo eugenesia involucra una dimensión futura, ínsita en el proceso reproductivo que, por definición, debía ser gestionado desde el poder. De ahí se infiere, entonces, que el poder legitimador de la eugenesia era tan significativo que su invocación resultaba funcional también a situaciones ajenas a la procreación, presente y futura, como lo demuestra la carta en cuestión. Allí, bajo el adjetivo "eugenésica" un cariñoso padre (¿acaso el mismísimo Saavedra?) escribe un libelo a su hija en el cual 
omite los previsibles consejos reproductivos, para concentrarse, en cambio, en fortalecer anquilosados roles de género (Saavedra, 1967).

Dos años después, la misma revista tardo eugénica argentina rescataba un mandato a "las jóvenes (inteligentes)", también redactado por Saavedra, donde se advertía respecto a los cuidados que debían tener las mujeres en edad de noviar (Sociedad..., 1969). En este contexto, de la saga de consejos de Saavedra recogidos y compartidos por el tardo eugenismo argentino, pueden traerse a colación sus curiosas respuestas ante la (preocupante) soltería de algunas mujeres, circunstancia que atribuye a llamativas cuestiones, que iban desde ser demasiado bonitas, orgullosas, coquetas, sosas o empalagosas hasta "porque la suegra las alaba o porque la suegra las espanta"; mientras que, otras mujeres lograban casarse porque sabían dar esperanzas y se daban a respetar, intuían los gustos de su pretendiente, hablaban poco y decían mucho (Saavedra, 1970).

Estos y otros imperativos de género, reforzados desde validaciones eugenésicas, serían retomados en un artículo publicado por Quirós en 1967, donde prescribía a la esposa abstenerse del trabajo fuera del hogar, salvo contadas excepciones. El fundamento de su propuesta se basaba en la inconveniencia de que entre los esposos existiera separación física o psíquica, espiritual o moral; no debiendo la esposa, por ende, ser "administrada por terceros, ni interesarse fuera de su hogar" (Bernaldo de Quirós, 1967).

\section{Consideraciones finales}

Los temores vinculados a la eventual expansión del comunismo en Occidente incrementaron, durante los años de la Guerra Fría, las preocupaciones de la Iglesia católica sobre la desintegración de la familia, responsabilizándose de ello, además, al liberalismo y al totalitarismo. En este sentido, y prediciendo un debilitamiento de la institución familiar tradicional ante los peligros que veía en la creciente disociación entre sexualidad y reproducción propia de la revolución contraceptiva (Segalen, 2013), la Acción Católica Argentina organizó en 1949 (recordemos, precisamente, el mismo año en el cual Bernaldo de Quirós presentara los anteproyectos de eugenización legislativa), la Cuarta Semana Nacional de Estudios Sociales bajo la sugerente consigna "Restauración social de la familia Argentina" (Valsecchi et al., 1950).

Las reflexiones allí vertidas retoman las vinculaciones inmanentes entre el mandato eclesiástico de constitución de una familia y la eugenesia latina; rechazándose empero, de plano, la "homicultura o cultivo del hombre por ser totalmente inconciliable con la dignidad humana" (Casiello, 1950, p.86). De esta manera, si se recuerda que la homicultura había sido fomentada desde los EEUU para establecer mecanismos de control de la inmigración a través de datos genéticos y somáticos (Álvarez Peláez, García González, 1999), bien pudo haber sido leída desde el ámbito latino como parte de la vertiente anglosajona de la eugenesia. Como contrapartida, la Acción Católica Argentina insistía en una especie de eugenesia voluntaria, cuya instrumentación óptima requería de la educación eugénica (Casiello, 1950, p.87).

La oposición al divorcio vincular y al tratamiento jurídico igualitario respecto a los hijos legítimos e ilegítimos constituyeron otros pilares argumentativos en pos de evitar la crisis de 
la familia argentina. Mientras tanto, se iba afirmando otra estrategia de intervención directa en la familia que, apuntando a un modelo ideal sostenido en valores cristianos, alejara a sus miembros de una hipotética degradación moral en ciernes. Para ello, el Episcopado fundaba, en 1951, dos organizaciones laicas, la Liga de Padres y la Liga de Madres de Familia (Vázquez Lorda, 2012), cuyos medios y fines resultaban concordantes con los del tardo eugenismo argentino en su ya irremediable viraje simbiótico hacia el catolicismo.

Así, a medida que el siglo XX iba avanzando, los principios sustentados por la eugenesia argentina se fueron confundiendo cada vez más con los de la doctrina católica; y desde ahí, el prototipo de familia eugénica indiferenciándo se del prototipo de familia confesional. Una demostración cabal de ello se encuentra en los tópicos abordados durante las tres Jornadas Sobre Eugenesia Integral, organizadas entre 1955 y 1970 por la Sociedad de Bernaldo de Quirós, en las cuales participaron reconocidos eugenistas del país y del exterior. Entre los distintos temas que se expusieron en las Primeras Jornadas, llevadas a cabo en noviembre de 1955, ocupó un lugar prioritario el tratamiento del par eugenesia-religión. $\mathrm{Al}$ respecto, el brasileño Theodolindo Castiglione planteaba que la eugenesia, aunque no tuviera las mismas finalidades de la religión, concurría a la formación del espíritu religioso, porque, según él, el perfeccionamiento físico, intelectual y moral era el mejor camino que aproximaba la criatura humana a Dios. Por su parte, la argentina Mercedes Rodríguez de Ginocchio coincidía en que las preocupaciones "científicas" de la eugenesia argentina tenían un sustrato común con las diversas religiones, especialmente con el cristianismo. Reforzando estas ideas, su compatriota, Gerardo Ruiz Moreno, enfatizaba los estrechos puntos de contacto entre la doctrina eugenésica integral positiva argentina y la católica, augurando que en el futuro "sus moralistas tendrán en cuenta, al referirse a la eugenesia, que la nuestra es enteramente ajena a todo procedimiento negativo (se llame eutanasia, esterilización, aborto etc.)"; de manera que la concepción asumida por la Sociedad Argentina de Eugenesia en 1945 era presentada como antagónica a la "condenada como negativa por la Iglesia"(Colombo, 1956a, p.95).

Unos pocos años después, en julio de 1961, tuvieron lugar las Segundas Jornadas, donde se abordaron temas tales como la creación de escuelas para padres, a las que se debía acudir desde antes del matrimonio con el objetivo de proporcionarles a los futuros contrayentes una sólida preparación eugenésica. Estarían a cargo de los consejeros humanistas egresados de la Facultad de Eugenesia (Segundas Jornadas..., 1961).

En términos pragmáticos, la Sociedad de Bernaldo de Quirós reclamaba la intervención oficial contra la mini-falda (La contra-audacia..., 1969, p.20); tema sobre el cual también se pronunciaría la Iglesia a través de las páginas de Criterio (Fevre, 1968). Y, ante la necesidad de instrumentar una campaña de "moralización" pública del ciudadano, esa sociedad haría suyas las intenciones de la Liga Pro Comportamiento Humano, fundada en 1960 por Francisco Antonio Rizzutto. En este sentido, la tardo eugenesia argentina expresaba su anhelo de eliminación, en todos los medios de comunicación masiva, de "manifestaciones indecorosas, ironías lesivas, juicios agresivos y recursos humorísticos de baja calidad" como también de las imágenes y expresiones sensualistas en la propaganda comercial (Por el..., 1968).

La integración entre eugenesia y doctrina eclesiástica se potenciaría hasta cercana la década de 1970, en cuyo marco Estudios Eugenésicos alababa la ilicitud de todo control 
artificial de la natalidad, tal como lo proclamaba la carta encíclica Humanae vitae, dictada por el papa Paulo VI (Bernaldo de Quirós, 1968a).

Procurando, desesperada e infructuosamente, retomar con éxito la tarea "patriótica" de restaurar la familia, en agosto de 1970 se celebraba la Tercera Jornada de Humanismo Eugenésico Integral, evento que se constituirá en el último de envergadura desarrollado por la institución emblemática del tardo eugenismo argentino. Entre los participantes se encontraba Paul Popenoe, quien se ocuparía de abordar la problemática asociada a los cambios en la familia (Tercera Jornada..., 1971). ${ }^{15}$

Asimismo, la ideología tardo eugénica local se confundiría con la de diversos grupos de presión y de poder habidos en el país durante las últimas décadas. Resultan notorias, por ejemplo, las compatibilidades e intertextualidades entre la Sociedad Argentina de Eugenesia y la ultraderechista Sociedad Argentina de Defensa de la Tradición, Familia y Propiedad, nacida en 1967. ${ }^{16}$ Esta organización anticomunista se originó en el país a instancias de un grupo de personas que, desde 1956, venían publicando Cruzada, revista conducida por Cosme Beccar Varela (h) (Scirica, 2014). Sus mentores recibieron al organizador de aquel movimiento internacional, el brasileño Plinio Correa de Oliveira, quien visitó el país en 1964 para dictar un ciclo de conferencias patrocinadas por la Federación Argentina de Entidades Democráticas Anticomunistas (Faeda) (TFP-Argentina, 1990, p.8). Y, sobre Faeda, debe advertirse que durante el periodo en análisis, Francisco Antonio Rizzutto (h) fue su vicepresidente mientras desempeñaba, en paralelo, la presidencia de la tan cercana al pensamiento de Quirós Liga Pro Comportamiento Humano, fundada por su padre, fallecido en 1965 (Bohoslavsky, 2015).

El empeño en el cumplimiento de ciertos propósitos permite localizar al discurso preconciliar y a un activo anticomunismo en el mismo horizonte de ideas de la doctrina tardoeugénica, como vimos cada vez más alejada de su inicial pretensión liberal y, en consecuencia, más concentrada en la imposición de una particular moral católica a toda la población. En este contexto, en 1971, Beccar Varela coincidiría con las coetáneas intervenciones de Bernaldo de Quirós calificando al mini-short como contrario a la moral; destacando, a su vez, la indisolubilidad del vínculo matrimonial monógamo así como el rol de la mujer, indefectiblemente limitado al hogar (Los rugidos..., 14 jun. 1971).

Así, el tardo eugenismo local, a través de la Sociedad Argentina de Eugenesia, y, con el apoyo (buscado o no) de organizaciones altamente reaccionarias, se convertiría en una usina de divulgación de principios eugénicos, desde la perspectiva católica, destinados a la corporización de un prototipo de familia heteronormativa, monógama, permanente, con clara división y jerarquización de roles y orientada, de manera exclusiva, a la finalidad procreativa. Estas premisas pervivieron en el tiempo, aun luego defenecida aquella sociedad resultando funcionales al mandato biopolítico de constitución de una familia "occidental y cristiana". Así, cabe advertir, que los efectos residuales del anclaje cultural de la eugenesia en las elites locales excedieron la vida institucional de la sociedad fundada por Quirós, permitiéndole al régimen golpista, instaurado en 1976, organizar su política de exterminio en un inmanente racialismo de sesgo eugenésico (Miranda, 2015). Demostración que desestima de plano, claro está, la caracterización de la vertiente tardo eugénica latina, como una versión edulcorada de la tesis de Galton. 


\section{NOTAS}

${ }^{1}$ Para ejemplificar, remitimos a los casos trabajados en Bashford, Levine (2010).

${ }^{2}$ Su verdadero nombre era Edoardo, cambiándolo por el de Agostino (en honor a San Agustín) cuando toma los primeros votos como fraile franciscano. Sobre Gemelli, pueden verse los textos: Comacini (2005), Bocci (2005) y Foschi, Giannone, Fiuliani (2013). Por otra parte, un artículo reciente relativiza la adscripción de Gemelli al fascismo, afirmándose que su principal objetivo era el de "proteger los intereses del Vaticano" (Pasqualini, 2016).

${ }^{3}$ Sobre el particular, puede verse Vallejo, Miranda (2014a, 2014b).

${ }^{4}$ Carlos Hermenegildo Bernaldo de Quirós y Ferreyra nació en Gualeguay (Provincia de Entre Ríos), en 1895, y murió en Buenos Aires, en 1973. Fue juez del crimen en la ciudad de La Rioja y ministro del Superior Tribunal de Justicia de esa provincia; asesor letrado del Banco Hipotecario Nacional; miembro fundador de la Asociación Argentina de Biotipologia, Eugenesia y Medicina Social; consejero del Museo Social Argentino y miembro de número de la Academia de Ciencias de Buenos Aires, de la Sociedad Boliviana de Eugenesia y de la Sociedad Mexicana de Eugenesia.

${ }^{5}$ Sobre las características evolutivas del mismo en Occidente, fundamentalmente a partir del siglo XVIII, resulta de cita ineludible la obra La police des familles (Donzelot, 1977).

${ }^{6}$ Ver los anteproyectos presentados por la Sociedad Argentina de Eugenesia y su exposición de motivos en Argentina (1950).

${ }^{7}$ Sobre Vallejo Nágera, ver Huertas $(2002,2012)$. Para una discusión en el mundo ibérico sobre el papel de la herencia/ambiente en la homosexualidad puede verse Cleminson (2008) y Cleminson, Vázquez García (2007).

${ }^{8}$ El concepto de responsabilidad procreacional en España sobre la prevención individual de enfermedades venéreas y su componente eugénico fue trabajado en Castejón Bolea (2011).

${ }^{9}$ La actuación de Spota en el campo eugénico argentino se mantuvo en el tiempo, reafirmando su postura conservadora de la familia y la sexualidad aún en la tardía década de 1960, con ocasión de dar un laudatorio discurso sobre la figura de Bernaldo de Quirós (Discurso..., 1966).

${ }^{10}$ Para un estudio desde esta perspectiva, situado en el caso español, puede verse Pérez López (1993, p.458).

${ }^{11}$ Este libro fue prologado por Gustavo Martínez Zubiría, un conocido escritor de ideas antisemitas.

${ }^{12}$ Concepto tomado de Lagarde y de los Ríos (2005).

${ }^{13}$ Sobre el tema, ver McLaren (1993), y, para Argentina Felitti (2012); Cosse, Felitti, Manzano (2010). Para el caso español, puede mencionarse el reciente libro de Ignaciuk, Ortíz Gómez (2016).

${ }^{14}$ La Eugenesia Integral era presentada como una variante ambiental, superadora de la tesis de Galton (Bernaldo de Quirós, 1957b, p.37).

${ }^{15}$ Paul Popenoe fue un biólogo estadounidense (1888-1979) que adscribió a la eugenesia anglosajona y defendió las políticas esterilizadoras. Con el avance del siglo, orientó sus investigaciones hacia el consejo matrimonial, constituyéndose en una figura de referencia para el eugenismo argentino.

${ }^{16}$ En 1960, se funda en Brasil la primer sociedad de este tipo, extendiéndose luego a Argentina, Australia, Bolivia, Canadá, Costa Rica, Ecuador, Paraguay, Perú, Portugal, España y Venezuela.

\section{REFERENCIAS}

ÁLVAREZ PELÁEZ, Raquel.

Francis Galton: herencia y eugenesia. Madrid: Alianza. 1988.

ÁLVAREZ PELÁEZ, Raquel; GARCÍA GONZÁLEZ, Armando.

En busca de la raza perfecta. Madrid: CSIC. 1999.

ARGENTINA.

Ministerio de Salud Pública de la Nación.

Eugenesia y derecho. Buenos Aires: Imprenta
Central del Ministerio de Salud Pública de la Nación. 1950.

BAS, Arturo M.

El cáncer de la sociedad. Buenos Aires: Sebastián de Amorrortu. 1932.

BASHFORD, Alison; LEVINE, Philippa (Ed.). The Oxford handbook of the history of eugenics. New York: Oxford University Press. 2010. 
BERNALDO DE QUIRÓS, Carlos.

Metodología y didáctica del humanismo eugenésico integral. Buenos Aires: Edición del autor. 1972.

BERNALDO DE QUIRÓS, Carlos.

La Iglesia de Roma y la regulación de la

natalidad. Estudios Eugenésicos, t.6, n.128, p.6. 1968a.

BERNALDO DE QUIRÓS, Carlos.

La promoción eugénica matrionial y familiar.

Estudios Eugenésicos, t.5, n.127, p.296. 1968b.

BERNALDO DE QUIRÓS, Carlos.

La preparación para el matrimonio. Estudios

Eugenésicos, t.5, n.122, p.252-253. 1967.

BERNALDO DE QUIRÓs, Carlos.

A propósito del proyecto de Tribunales de

Familia. Estudios Eugenésicos, t.5, n.112, p.175-

176. 1966.

BERNALDO DE QUIRÓS, Carlos.

Bases y principios para padres e hijos. Buenos

Aires: Legión Blanca. 1960a.

BERNALDO DE QUIRÓS, Carlos.

Los medios desesperados, la "integración

social" y la vida eugenésica de la mujer. Estudios

Eugenésicos, t.4, n.86, p.319-322. 1960b.

BERNALDO DE QUIRÓS, Carlos.

Bodas de plata de la Sociedad Mexicana de

Eugenesia. Estudios Eugenésicos, t.4, n.65, p.156. 1957a.

BERNALDO DE QUIRÓS, Carlos.

La degradación cosista del hombre. Buenos Aires: Edición del autor. 1957b.

BERNALDO DE QUIRÓS, Carlos.

Eugenesia. In: AAVV. Enciclopedia jurídica Omeba, t.11. Buenos Aires: Bibliográfica Omeba. p.331335. s.f.

BOCCI, María.

Gemelli. In: De Grazia, Victoria; Luzzatto, Sergio (A cura di). Dizionario del fascismo, t.1. Torino: Einaudi. p.577-579. 2005.

BOHOSLAVSKY, Ernesto.

It's only rock and roll, but I (dis)like it: anticomunismo, conservadurismo moral y persecución al primer rock argentino en la década de 1960. In: Fiuza, Alexandre et al. (Coord.). Anais do II Congresso Internacional de Estudos do Rock. Cascavel: Unioeste, 2015. Disponible en: http:// www.congressodorock.com.br/evento/anais/2015/ atual.html. Acceso en: 16 mayo 2017. 2015.

CASIELLO, Juan.

La familia frente a la legislación argentina. In: Valsecchi, Francisco et al. Restauración social de la familia argentina. Buenos Aires: Junta Central de la Acción Católica Argentina. p.77-93. 1950.
CASTEJÓN BOLEA, Ramón.

Los debates sobre la prevención individual de las enfermedades venéreas. In: Guereña, Jean Louis (Ed.). La sexualidad en la España contemporánea, 1800-1950. Cádiz: Servicio de Publicaciones de la Universidad de Cádiz. p.121-148. 2011.

CLEMINSON, Richard.

Anarquismo y sexualidad (España, 1900-

1939). Cádiz: Servicio de Publicaciones de la

Universidad de Cádiz. 2008.

CLEMINSON, Richard; VÁZQUEZ GARCÍA, Francisco.

"Los invisibles": a history of male homosexuality in Spain, 1850-1939. Cardiff: University of Wales Press. 2007.

COLOMBO, Leonardo.

Las primeras jornadas de eugenesia integral: temas jurídicos tratados en las mismas. Estudios Eugenésicos, t.4, n.58, p.93-98. 1956a.

COLOMBO, Leonardo.

Las primeras jornadas de eugenesia integral: temas jurídicos tratados en las mismas. La Ley, t.81, p.697-701. 1956b.

COLOMBO, Leonardo.

Un anteproyecto de reformas eugenésicas al Código Civil. La Ley, t.54, p.915-923. 1949.

COMACINI, Gemma.

Gemelli: il Machiavelli di Dio. Milán: Rizzoli. 2005.

COSSE, Isabella; FELITTI, Karina; MANZANO, Valeria (Ed.).

Los '60 de otra manera: vida cotidiana, género y sexualidades en la Argentina. Buenos Aires: Prometeo. 2010.

DÍAZ DE GUIJARRO, Enrique.

El impedimento matrimonial de enfermedad (matrimonio y eugenesia). Buenos Aires:

Guillermo Kraft. 1944.

DISCURSO...

Discurso del profesor titular de genética y embriología de la facultad, Dr. Benjamín B. Spota, en el homenaje al Dr. Carlos Bernaldo de Quirós. Estudios Eugenésicos, t.5, n.111, p.166. 1966.

DOMENECH, Armando.

Razones eugenésicas para el estudio de la sexología. Estudios Eugenésicos, t.4, n.75, p.231238. 1958.

DONZELOT, Jacques.

La police des familles. Paris: Minuit. 1977.

EL HOMOSEXUALISMO...

El homosexualismo legalizado en Inglaterra.

Estudios Eugenésicos, t.5, n.122, p.251-252. 1967. 
FELITTI, Karina.

La revolución de la píldora: sexualidad y política en los sesenta. Buenos Aires: Edhasa. 2012.

FEVRE, Fermín.

La ola hippy. Criterio, año 41, n.1542, p.119-120. 1968.

FOSCHI, Renato; GIANNONE, Anna; FIULIANI, Alessia.

Italian psychology under protection: Agostino Gemelli between catholicism and fascism. History of Psychology, v.16, n.2, p.130-144. 2013.

GEMELLI, Agostino.

L'Eugenetica e la morale cattolica: a proposito del primer Congresso Italiano di Eugenetica Sociale. Vita e Pensiero, t.15, n.12, p.731-750. 1924.

GOMÁ, Isidro, cardenal.

El matrimonio: explicación dialogada de la encíclica Casti connubbi. Barcelona: Rafael Casulleras. 1943.

GUTIÉRREZ, María Alicia.

Derechos sexuales y reproductivos. In: Gamba, Susana (Coord.). Diccionario de estudios de género y feminismos. Buenos Aires: Biblos, p.87-89. 2009.

HUERTAS, Rafael.

De la higiene mental a la higiene de la raza: psiquiatría y eugenesia en el nacional catolicismo español y su relación con la Argentina. In: Miranda, Marisa; Vallejo, Gustavo (Dir.). Una historia de la eugenesia: Argentina y las redes biopolíticas internacionales, 1912-1945. Buenos Aires: Biblos. p.239-258. 2012.

HUERTAS, Rafael.

Los médicos de la mente. Madrid: Nívola. 2002.

IGNACIUK, Ágata; ORTÍZ GÓMEZ, Teresa. Anticoncepción, mujeres y género: la "píldora" en España y Polonia, 1960-1980. Madrid: Los Libros de la Catarata. 2016.

LA CONTRA-AUDACIA...

La contra-audacia femenina (la "mini-falda"). Estudios Eugenésicos, t.6, n.130, p.19-20. 1969.

LAGARDE Y DE LOS RÍOS, Marcela.

Los cautiverios de las mujeres: madresposas, monjas, putas, presas y locas. México: Unam. 2005.

\section{LA POLÍTICA...}

La política de la revolución argentina en salarios y subsidios. Estudios Eugenésicos, t.6, n.130, p.24. 1969.

LOS RUGIDOS...

Los rugidos del león rampante: Sociedad Argentina de Defensa de la Tradición, Familia y Propiedad. Siete Días Ilustrados. Disponible en: http://www.magicasruinas.com.ar/revistero/ locales/tradicion-familia-propiedad.htm. Acceso en: 13 mar. 2018. 14 jun. 1971.

MCLAREN, Angus.

Historia de los anticonceptivos. Madrid: Minerva. 1993.

MIRANDA, Marisa.

Reflexiones en torno a la construcción de discursos inmunitarios en ámbitos dictatoriales: el caso argentino, 1976-1983. In: Leyton, César; Palacios, Cristián; Sánchez, Marcelo (Ed.). Bulevar de los pobres: racismo científico, higiene y eugenesia en Chile e Iberoamérica, siglos XIX y XX. Santiago de Chile: Museo Nacional de Odontología; Ocho Libros. p.306-317. 2015.

MIRANDA, Marisa.

Noviazgo y eugenesia en ámbitos latinos: "casar selectos para parir selectos". Cadernos de Pesquisa Interdisciplinar em Ciências Humanas, v.15, n.107, p.49-78. 2014.

MIRANDA, Marisa.

La tardo-eugenesia en Argentina: un enfoque desde la longue durée. Arbor, v.189, n.764. Disponible en: http://dx.doi.org/10.3989/ arbor.2013.764n6011. Acceso en: 13 mar. 2018. 2013.

MIRANDA, Marisa.

Doxa, eugenesia y derecho en la Argentina de posguerra, 1949-1957. In: Vallejo, Gustavo; Miranda, Marisa (Comp.). Políticas del cuerpo: estrategias modernas de normalización del individuo y la sociedad. Buenos Aires: Siglo XXI. p.97-129. 2007.

MIRANDA, Marisa; BARGAS, María Luján. Mujer y maternidad: entre el rol sexual y el deber social (Argentina, 1920-1945). Locus, v.17, n.2, p.75-101. 2011.

MIRANDA, Marisa; VALLEJO, Gustavo (Dir.). Una historia de la eugenesia: Argentina y las redes biopolíticas internacionales. Buenos Aires: Biblos. 2012.

NASIO, Juan.

Los contraceptivos y el sentido moral en la investigación médico-científica. Estudios Eugenésicos, t.5, n.117, p.211-214. 1966.

OBJETIVOS...

Objetivos políticos (fines de la Revolución). Anales de Legislación Argentina, t.26B, p.757. 1967.

OTRA VEZ ...

Otra vez el homosexualismo. Estudios Eugenésicos, t.5, n.124, p.273. 1968.

PASQUALINI, Mauro.

Un enigma llamado Agostino Gemelli: catolicismo, fascismo y psicoanálisis en la 
Italia de entreguerras. História, Ciências, Saúde Manguinhos, v.23, n.4, p.1059-1075. 2016.

PÉREZ LÓPEZ, Jesús.

El discurso pedagógico relativo a la sexualidad en España, 1940-1962. Tesis (Doctorado en Sociología) - Universidad Complutense de Madrid, Madrid. 1993.

POR EL...

Por el saneamiento de las costumbres. Estudios Eugenésicos, t.5, n.127, p.298. 1968.

ROSSI, Arturo.

Tratado teórico práctico de biotipología y ortogénesis, t.1. Buenos Aires: Ideas. 1944.

SAAVEDRA, Alfredo M.

Temas de eugenesia. Estudios Eugenésicos, t.6, n.136, p.70-71. 1970.

SAAVEDRA, Alfredo M.

Carta eugenésica a una hija que se casa (de México). Estudios Eugenésicos, t.5, n.118, p.226. 1967.

\section{SCIRICA, Elena.}

El grupo "Cruzada" - "Tradición Familia y Propiedad": TFP y otros emprendimientos laicales tradicionalistas contra los sectores tercermundistas: una aproximación a sus prácticas y estrategias de difusión en los años sesenta. Memoria y Sociedad, v.18, n.36, p.66-81. 2014.

SEGALEN, Martine.

Sociología de la familia. Mar del Plata: Eudem. 2013.

\section{SEGUNDAS JORNADAS...}

Segundas Jornadas Argentinas de Humanismo Eugenésico Integral. Estudios Eugenésicos, t.4, n.89, p.342-357. 1961.

SEOANE, José B.

El placer y la norma: genealogía de la educación sexual en la España contemporánea: orígenes, 1800-1920. Barcelona: Octaedro. 2006.

\section{SOCIEDAD...}

Sociedad Mexicana de Eugenesia, A.C.: para las jóvenes (inteligentes). Estudios Eugenésicos, t.6, n.133, p.48. 1969.

SPOTA, Benjamín B.

La eugenesia positiva en lo hereditario y ambiental. La Semana Médica, año 54, n.2729, p.297-308. 1947.

STEPAN, Nancy Leys.

The hour of eugenics: race, gender, and nation in Latin America. Ithaca: Cornell University Press. 1991.

STERN, Alexandra Minna.

From mestyzophilia to biotypology:

racialization and science in Mexico, 1920-
1960. In: Appelbaum, Nancy; Macpherson, Anne; Rosemblatt, Karin (Ed.). Race and nation in modern Latin America. North Carolina: University of North Carolina Press. p.187-210. 2003.

SUÁREZ Y LÓPEZ GUAZO, Laura.

Eugenesia y racismo en México. México: Unam. 2005.

SUÁREZ Y LÓPEZ GUAZO, Laura.

La influencia de la Sociedad Eugénica Mexicana en la educación y en la medicina social. Asclepio, v.51, n.2, p.51-84. 1999.

TERCERA JORNADA...

Tercera Jornada Argentina de Humanismo Eugenésico Integral: con algunas conclusiones de la Comisión Revisora. Estudios Eugenésicos, t.7, p.1-495. 1971.

TFP-Argentina.

Tradición, Familia y Propiedad-Argentina. $L a$ TFP en combate contra la ambigüedad y el caos ideológico-político que impiden a la nación alcanzar su destino de grandeza cristiana. Disponible en: http://www.pliniocorreadeoliveira.info/ GestaES_0201Argentina.htm.WQt2FIU1_IU. Acceso en: 13 mar. 2018. 1990.

TURDA, Marius; GILLETTE, Aaron.

Latin eugenics in comparative perspective. London: Bloomsbury. 2014.

VALLEJO, Gustavo.

La coerción disimulada: la propaganda radial de la eugenesia en la Argentina de entreguerras. In: Miranda, Marisa; Girón Sierra, Álvaro (Coord.). Cuerpo, biopolítica y control social: América Latina y Europa en los siglos XIX y XX. Buenos Aires: Siglo XXI. p.181-206. 2009.

VALLEJO, Gustavo; MIRANDA, Marisa. Enseñando a custodiar el buen nacer: los estudios universitarios de eugenesia en Argentina, 1942-1980. Varia Historia, v.33, n.61, p.49-78. 2017.

VALLEJO, Gustavo; MIRANDA, Marisa. Dirigir el azar: Iglesia católica, evolucionismo y eugenesia en Argentina. In: Puig-Samper, Miguel Ángel; Orrego, Francisco; Ruiz, Rosaura; Uribe, Alfredo (Ed.). "Yammerschuner": Darwin y la darwinización en Europa y América Latina. Madrid: Doce Calles. p.327-344. 2014a.

VALLEJO, Gustavo; MIRANDA, Marisa. Iglesia católica y eugenesia latina: un constructo teórico para el control social (Argentina, 19241958). Asclepio, v.66, n.2, p.1-12. 2014b.

VALLEJO, Gustavo; MIRANDA, Marisa. La eugenesia y sus espacios institucionales en Argentina. In: Miranda, Marisa; Vallejo, Gustavo (Comp.). Darwinismo social y eugenesia en el 
mundo latino. Buenos Aires: Siglo XXI. p.145192. 2005.

VALSECCHI, Francisco et al.

Restauración social de la familia argentina. Buenos Aires: Junta Central de la Acción Católica Argentina. 1950.
VÁZQUEZ LORDA, Lilia Mariana.

Intervenciones e iniciativas católicas en el ámbito familiar: las ligas de madres y padres de familia (Argentina, 1950-1970). Tesis (Maestría en Historia) - Universidad de San Andrés, Buenos Aires. 2012.

\section{$\rightarrow \rightarrow \rightarrow<<<$}

